\title{
Characterisation of Cancer Support and Rehabilitation Programmes: A Swedish Multiple Case Study
}

\author{
Linda Berg*, Margaretha Jenholt Nolbris, Ingalill Koinberg, Christina Melin-Johansson, \\ Anders Möller and Joakim Öhlén
}

Institute of Health and Care Sciences, The Sahlgrenska Academy, University of Gothenburg, Gothenburg, SE 40530, Sweden

\begin{abstract}
Cancer support and rehabilitation are suggested to be an integral part of cancer care strategies. This study focuses on comparativeness of cancer support and rehabilitation programmes. The aim of this study was to analyse available cancer support and rehabilitation programmes in Sweden presented as complementary to cancer rehabilitation at cancer clinics. A multiple case study design was chosen in order to inquire the small number of existing supportive and rehabilitative cancer programmes. Based on the structures, processes and outcomes of the nine included programmes, three types of cancer support and rehabilitation programmes were identified: multimodal rehabilitation, comprehensive cancer support and art therapy. Cancer support and rehabilitation programmes offer a variety of activities and therapies which are highly valuable and relevant for people with cancer. The typology of cancer support and rehabilitation programmes and comparability between programmes need further inquiry.
\end{abstract}

Keywords: Cancer, cancer programme, case study, rehabilitation, support.

\section{INTRODUCTION}

Psychosocial problems are found to be significant elements for patients along the cancer journey, including mood disturbance, symptom distress [1-5] and fear of cancer relapse [6]. Cancer support and rehabilitation are suggested to be integral parts of cancer care strategies, although patients' rehabilitation needs are in many cases not met by the healthcare system or fully utilised by patients [7]. However, knowledge is scarce concerning different kinds of cancer support and rehabilitation programmes, comparability consequently being needed for reliable and valid evaluations. This study therefore focuses on comparativeness of cancer support and rehabilitation programmes.

'Cancer rehabilitation' is a subspecialty of rehabilitation medicine, defined as concerned with restoring and maintaining the highest possible level of function, independence, and quality of life for patients at all stages of cancer, including those undergoing potentially curative therapy and those receiving palliative care, as well as cancer survivors [8, 9]. Cancer rehabilitation is based on multimodal areas encompassing physical, psychological, social and existential dimensions, preventing consequences of cancer and treatment [10]. 'Support' is characterised by diverse and imprecise usage, although encompassing four principal meanings: comfort, strengthening, maintenance and advocacy [11].

*Address correspondence to this author at the Institute of Health and Care Sciences, The Sahlgrenska Academy, University of Gothenburg, Gothenburg, SE 40530, Sweden; Tel: + 46 - 317866082;

E-mail: linda.berg@fhs.gu.se
A number of studies describe different multidimensional supportive and rehabilitation programmes led by multidisciplinary teams, targeting unspecific diagnosis of cancer e.g. $[5,12,13]$ and cancer survivors [14-16] or specific diagnosis of cancer, including prostate [17], breast [18, 19] and gynecological cancer [20]. Frequently reported specific therapies included in supportive and rehabilitation programmes are cycling, walking or strength training $[5,16]$. The combinations of physical exercise and diet [15], as well as group-based psychosocial interventions with health education, art therapy and relaxation $[1,20]$ are also described. Further, the significance of complementary medicine (CM) and complementary therapy (CT) and its integration in supportive care and rehabilitation is highlighted e.g. $[3,5,21]$. In this way, specific therapies integrated in supportive and rehabilitation programmes also include dietary advising, qigong and yoga interventions [5, 21] and massage [4], as well as alternative medical systems such as anthroposophy and herbal medicine [3].

Effects from participation in specific supportive and rehabilitation programmes are reported. Outcomes include reduction of symptom distress (anxiety, fatigue and sleep disturbances) increase of physical functioning, energy levels, body weight, mood, survival rate, ability to return to work, health-related quality of life and general quality of life and well-being [3-5, 16, 21, 22]. Improvement or deterioration of interventions is multifaceted and the specific result of an intervention is difficult to demonstrate due to progression of the disease and treatment-related outcomes [3]. However, methodological challenges for evaluation of cancer support and rehabilitation programmes are considerable, and clinical expertise based on observations with qualitative analyses is suggested to complement clinical trials [23]. 
In Sweden, an increasing number of people are diagnosed with cancer and cured, and also live longer with their cancer. This is a new situation in cancer care, emphasising a demand for developing rehabilitation strategies. At the same time, rehabilitation resources for cancer patients are limited and today there is inequality as to the kind of rehabilitation offered $[10,24]$. If a patient is offered rehabilitation, this is provided by many different actors, such as the hospital, the cancer society, private rehabilitation organisations or at community level [10]. Healthcare has a tradition of obvious top-down governance, which currently tends towards regionalisation and decentralisation. While cancer rehabilitation within the frame of cancer clinics is comparatively regulated under national, regional and local guidelines, cancer support and rehabilitation programmes complementary to the cancer clinic's activities are not included in such regulation. In the debate, we notice financial arguments for leaving cancer support and rehabilitation programmes outside cancer clinics; these programmes are considered too expensive and with unknown outcomes. At the public health level, however, emphasis on rehabilitation is very apparent, with initiatives for returning to work from sick leave (principally due to neck, back and shoulder disorders and mental illness) but not from cancer. This is because cancer patients have a more complex situation, living as they do with long-term physical and psychological side effects, and issues concerning returning to work are not raised by healthcare professionals in early discussions [24].

The process of cancer rehabilitation is unclear in terms of whether it is needed at all, the extent to which it is required, its timing, and what type of rehabilitation is offered [25]. In addition, the existing ambiguity about comparability of cancer support and rehabilitation programmes contributes to difficulties for several stakeholders. For patients to become informed and knowledgeable about existing rehabilitation programmes, all stakeholders must be included in the decision-making regarding participation in such programmes. If they are, they must also be assisted in differentiating between different programmes; for example, healthcare providers in relation to making recommendations to patients; funding bodies as to which complementary cancer support and rehabilitation programmes to support, and policy makers so as to provide a sympathetic regulatory framework. The ultimate question is which patients to refer and recommend to which service, and when during the cancer trajectory; this necessitates evidence in cancer care.

The aim of this study was to analyse available cancer support and rehabilitation programmes in Sweden presented as complementary to cancer rehabilitation at cancer clinics. The research questions to be answered were: How can existing support and rehabilitation programmes be characterised pertaining to structure, processes and outcomes? Can types of programmes be discerned, and if so, how can a typology of cancer support and rehabilitation programmes be described?

\section{MATERIAL AND METHODS}

\section{Design}

A multiple case study design was chosen in order to inquire the small number of existing supportive and rehabilitative cancer programmes. This was to allow for analysis of complex process and outcome issues based on the incorporation of different perspectives [26] and to focus on both commonalities and particularities, drawing on different variables [27]. The unit of inquiry was consequently the included cases. The process followed the steps described by [26]: selection of cases, designing data collection protocols, conducting case studies and writing case reports, making cross-case comparisons, and finally, identifying strengths and weaknesses and policy and research implications.

\section{Selection of Cases}

Inclusion criterion for this study was support- and rehabilitation programmes in operation from January 1 to June 30, 2011 which received financial support from cancer foundations. Exclusion criteria were (a) peer cancer support groups (b) programmes established within county councils' healthcare. The researchers contacted key representatives of adult cancer care organisations in various regions of Sweden in order to gain acquaintance with all existing support and rehabilitation programmes in the country used by cancer patients. In addition, internet searches were performed concerning existing support and rehabilitation programmes, after which these were contacted and a key contact person in each organisation was identified [26]. In most cases, this person was the director of the organisation. These key persons were also asked for their knowledge of similar programmes; however, no additional programmes were identified this way. Eleven programmes fulfilled the criteria but two declined to participate, one of these having been contacted several times and declining on the grounds of lack of time, the other on the grounds that they were afraid the organisation might be misunderstood if it took part, and risked losing members. In total, nine support and rehabilitation programmes were included, located from the North to the South of Sweden.

\section{Designing Data Collection Protocol}

In order to develop an interview guide, a literature review was conducted after selecting relevant sources [11, 28, 29]. The interview guide was constructed in line with $[30,31]$ in terms of structure, process and outcomes. The developed interview guide consisted of 40 open-ended questions related to (a) structure: background and objectives of the programme, participant characteristics, financing, marketing, staffing and competence, knowledge sources for the design of the programme, organisation of programme, evaluation methods, visions and future expectations, (b) process: activities, therapies, forms of client participation, and (c) outcomes: external and internal analyses of client-reported outcomes. The questions were piloted in four interviews with representatives from one patient cancer support group and three county-council run support programmes. After pilot testing the interview guide, one question was added concerning supervision of staff.

\section{Data Collection for Case Studies}

Telephone interviews were performed and audiorecorded with the identified key representatives of the nine programmes, each interview lasting between 16 and 59 
minutes (mean 33 minutes). During the interviews, written material describing the programme and its outcomes was requested. Brochures, websites and evaluation reports were mailed or e-mailed by two representatives (case 2,4 ) to one of the researchers.

\section{Case Reports and Cross-Case Comparisons}

The recordings were transcribed verbatim and all data were compiled into the areas of structure, process and outcomes [30, 31]. The analysis of data related to each of the cases was descriptive and first analysed separately as a single case. This analysis was started independently by all the researchers, and continued with comparisons in team meetings until consensus regarding the case reports was reached. A cross-case analysis followed [26], seeking similarities and differences between the cases and identifying a tentative typology of four types of programmes, which was analysed in relation to theoretical aspects of rehabilitation and support [11]. Further comparisons of the data sources from each case culminated in a typology of three types of programmes.

\section{Ethics and Consent}

The study was carried out in accordance with basic ethical guidelines, i.e. the Helsinki Declaration [32]. Information about the study and procedure was given and consent to participate requested in the initial telephone contact with the key representatives of the included programmes. The interview guide was mailed or e-mailed to the organisations that gave their consent so that the participants could familiarise themselves with the questions before the interview and discuss them with colleagues.

\section{RESULTS}

Based on the structures, processes and outcomes of the nine included programmes, three types of cancer support and rehabilitation programmes were identified: multimodal rehabilitation (cases 1-4), comprehensive cancer support (cases 5, 8, 9) and art therapy (cases 6,7) (Table 1).

\section{Structure}

The included cancer support and rehabilitation programmes had been established for between one and 26 years, with a median of 16 years. The majority of programmes had collaborative partners and diverse funding sources. All programmes included participants with various cancer diagnoses in different stages, during or after cancer treatment. Most programmes had people with cancer aged 18 and over as their only target group (cases 1,2,5,6,9), while others welcomed people with long term conditions and rehabilitation needs of other kinds as well as cancer (cases 3,4,7,8) (Table 1).

Participants were referred to healthcare provider programmes in all nine cases. In four programmes (cases 2, 4, 8, 9) participants could also apply individually, which could stem from own initiative as well as recommendation from others (Table 1). All programmes were marketed through websites and written notices or advertised in newspapers and distributed in brochures or newsletters.

Minor distinguishing characteristics between the three types of programmes were identified: multimodal rehabilitation programmes provided a broad range of combined therapies; comprehensive cancer support programmes provided a combination of few therapies including single body-based therapies; art therapy programmes offered support by means of one specific therapy. Knowledge about self-healing and recovery capacity of the body was only stated as an objective for one programme (case 3), while the objectives for the other programmes were related to multimodal rehabilitation, as well as to comprehensive cancer support (Table 1).

All programmes were reported to base their service on clinical and theoretical evidence in general. Three multimodal rehabilitation programmes also referred specifically to anthroposophy (case 1), salutogenic and holistic health (case 2) and holistic principles (case 9) for theoretical foundations.

The multimodal rehabilitation and comprehensive cancer-support oriented programmes were organised as fullday programmes with accommodation for durations of between one week (weekdays/excluding weekends) and three weeks (Table 1). The art therapy programmes were run with one weekly session for up to eight weeks.

Most of the multimodal rehabilitation and comprehensive cancer-support oriented programmes (cases 1, 2, 4, 8, 9) had multi-professional staff, including physicians and various health professionals (Table 1). The art therapy programmes were led by art therapists alone. Multi-professional teams included administration and service staff, registered nurses, nurse assistants, physicians, physiotherapists, occupational therapists, dieticians, psychologists, social workers, psychotherapists, priests, art therapists, music therapists, symbol therapists and anthroposophist therapists. Various numbers of staff were involved $(1-100)$. The two smaller programmes, staffed with 2 to 5 people (cases 3, 5) both did not include physicians in the team (Table 1).

Some programmes offered activities and therapies for families with children (case 2) and spouses (cases 1, 2, 8, 9), as well as for couples (cases 1, 2, 5, 8,9). Other programmes welcomed significant others whenever possible in all activities and therapies (cases 1, 2, 4, 8, 9) (Table 2).

\section{Processes}

Multimodal rehabilitation and comprehensive support programmes covered physical therapies, medical care, creative therapies and counselling. Art therapy programmes combined their specific form of therapy with counselling (Table 2). Active participation was an essential characteristic of activities according to all the representatives.

The only common objective of the programmes was supporting self-help through a holistic approach and providing time for reflection, and this was the only stated objective for the art therapy programmes (cases 6, 7). Maintaining and enhancing health through physical, creative and cultural activities were common features of the 
Table 1. Structure of the Programmes

\begin{tabular}{|c|c|c|c|c|c|c|c|c|c|}
\hline \multirow{2}{*}{ Cases } & \multicolumn{4}{|c|}{$\begin{array}{c}\text { Multimodal } \\
\text { Rehabilitation }\end{array}$} & \multicolumn{3}{|c|}{$\begin{array}{l}\text { Comprehensive } \\
\text { Support }\end{array}$} & \multicolumn{2}{|c|}{$\begin{array}{c}\text { Art } \\
\text { Therapy }\end{array}$} \\
\hline & 1 & 2 & 3 & 4 & 5 & 8 & 9 & 6 & 7 \\
\hline \multicolumn{10}{|l|}{ Objectives } \\
\hline Supporting self-help, holistic approach and time for reflection & $\mathrm{X}$ & $\mathrm{X}$ & $\mathrm{X}$ & $\mathrm{X}$ & $\mathrm{X}$ & $\mathrm{X}$ & $\mathrm{X}$ & $\mathrm{X}$ & $\mathrm{X}$ \\
\hline Regaining joy of living & & $\mathrm{X}$ & & $\mathrm{X}$ & $\mathrm{X}$ & & & & \\
\hline Active participation in the rehabilitative process & $\mathrm{X}$ & $\mathrm{X}$ & & & & $\mathrm{X}$ & $\mathrm{X}$ & & \\
\hline Coping with stressors, strengthening & & & $\mathrm{X}$ & & & & $\mathrm{X}$ & & \\
\hline Health resources and regaining energy knowledge about interplay between body and soul & & $\mathrm{X}$ & & & $\mathrm{X}$ & & & & \\
\hline Increased knowledge about cancer and related reactions & & $\mathrm{X}$ & & & $\mathrm{X}$ & & & & \\
\hline \multicolumn{10}{|l|}{ Target Client Group } \\
\hline Cancer & $\mathrm{X}$ & $\mathrm{X}$ & $\mathrm{X}$ & $\mathrm{X}$ & $\mathrm{X}$ & $\mathrm{X}$ & $\mathrm{X}$ & $\mathrm{X}$ & $\mathrm{X}$ \\
\hline Long-term illness & & & & $\mathrm{X}$ & & & & & \\
\hline Health promotion & & & & & & $\mathrm{X}$ & & & \\
\hline Traffic injuries & & & & & & & & & $\mathrm{X}$ \\
\hline Significant others & $\mathrm{X}$ & $\mathrm{X}$ & & $\mathrm{X}$ & $\mathrm{X}$ & $\mathrm{X}$ & & & \\
\hline Number of participants annually in total & 160 & 788 & 144 & 100 & 100 & 370 & 300 & 24 & 24 \\
\hline \multicolumn{10}{|l|}{ Organization and Frequency } \\
\hline Multi-professional teams without physician & & & $\mathrm{X}$ & & $\mathrm{X}$ & & & & \\
\hline Single profession & & & & & & & & $\mathrm{X}$ & $\mathrm{X}$ \\
\hline Number of staff in total & $\begin{array}{l}100 \\
2-5\end{array}$ & & $\begin{array}{l}13 \\
30\end{array}$ & & $\begin{array}{l}3-5 \\
35\end{array}$ & & $\begin{array}{c}30 \\
2\end{array}$ & & 1 \\
\hline
\end{tabular}

programmes oriented towards multimodal rehabilitation as well as comprehensive cancer support (Table $\mathbf{1}$ ).

\section{Outcomes}

All programmes utilised non-standardised satisfaction questionnaires for evaluation and all but one (case 6) utilised combinations of methods (Table 3). Six programmes utilised standardised instruments, and three instruments were identified: HAD [33] assessing levels of anxiety and depression SF-36 [34] and EQ-5D [35] estimating healthrelated quality of life was the most common and used by three programmes (cases 1, 4, 9). Three programmes (cases $1,5,7$ ) conducted supplementary evaluating interviews with participants. No differences between method of evaluation and type of programmes were identified.
All the representatives of the programmes reported increased self-reported health outcomes and very high satisfaction following participation in the programmes. Participant satisfaction was reported in evaluation as emphasising a gain in long term physical and psychological strength as well as the development of skills supporting recovery and a return to previous levels of occupational activities. Further, participants from all the programmes highly valued the peer community and feeling of togetherness.

\section{DISCUSSION}

The main contribution of the present study is that the existing cancer rehabilitation programmes besides public cancer clinic programmes have been mapped and can be 
Table 2. Overview of Activities and Therapies in the Programmes

\begin{tabular}{|c|c|c|c|c|c|c|c|c|c|}
\hline \multirow{2}{*}{ Cases Activities and Therapies } & \multicolumn{4}{|c|}{ Multimodal Rehabilitation } & \multicolumn{3}{|c|}{ Comprehensive Support } & \multicolumn{2}{|c|}{ Art Therapy } \\
\hline & 1 & 2 & 3 & 4 & 5 & 8 & 9 & 6 & 7 \\
\hline 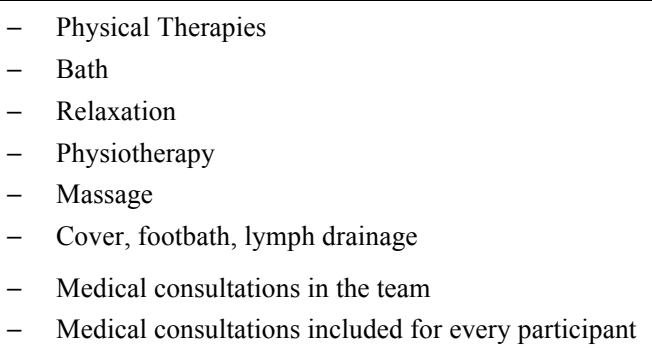 & $\begin{array}{l}X \\
X \\
X \\
X \\
X \\
X\end{array}$ & $\begin{array}{l} \\
X \\
X\end{array}$ & $\begin{array}{l}X \\
X\end{array}$ & $\begin{array}{l}X \\
X \\
X \\
X\end{array}$ & $\mathrm{X}$ & $\mathrm{X}$ & $\begin{array}{l}X \\
X\end{array}$ & & \\
\hline $\begin{array}{l}\text { Creative Therapies } \\
-\quad \text { Music therapy } \\
-\quad \text { Art therapy } \\
-\quad \text { Creative activities }\end{array}$ & $\mathrm{X}$ & $\mathrm{X}$ & $\begin{array}{l}X \\
X \\
X\end{array}$ & & $\mathrm{X}$ & & & $\mathrm{X}$ & $\mathrm{X}$ \\
\hline $\begin{array}{ll}\text { Counselling } \\
- & \text { Individual } \\
- & \text { Group } \\
- & \text { Couples } \\
- & \text { Follow-up by telephone }\end{array}$ & $\begin{array}{l}X \\
X \\
X\end{array}$ & $\begin{array}{l}X \\
X \\
X\end{array}$ & $\begin{array}{l}\mathrm{X} \\
\mathrm{X} \\
\mathrm{X}\end{array}$ & $\begin{array}{l}X \\
X\end{array}$ & $\begin{array}{l}X \\
X \\
X \\
X\end{array}$ & $\begin{array}{l}X \\
X\end{array}$ & $\begin{array}{l}X \\
X\end{array}$ & $\mathrm{X}$ & $\mathrm{X}$ \\
\hline
\end{tabular}

Table 3. Evaluation Methods

\begin{tabular}{|c|c|c|c|c|c|c|c|c|c|}
\hline \multirow{2}{*}{ Evaluation Methods } & \multicolumn{9}{|c|}{ Case number } \\
\hline & 1 & 2 & 3 & 4 & 5 & 8 & 9 & 6 & 7 \\
\hline $\begin{array}{l}\text { Standardised instruments } \\
\text { EQ5D - at admission and discharge a } \\
\text { HAD - at admission and discharge } \\
\text { SF-36 - at admission, discharge and } 2 \text { years after }\end{array}$ & $\mathrm{X}$ & $\mathrm{X}$ & & $\mathrm{X}$ & & $\mathrm{X}$ & $\mathrm{X}$ & & $\mathrm{X}$ \\
\hline Non-standardised satisfaction questionnaires & $\mathrm{X}$ & $\mathrm{X}$ & $\mathrm{X}$ & $\mathrm{X}$ & $\mathrm{X}$ & $\mathrm{X}$ & $\mathrm{X}$ & $\mathrm{X}$ & $\mathrm{X}$ \\
\hline $\begin{array}{l}\text { Interviews } \\
\text { Individual at admission } \\
\text { Individual at discharge } \\
\text { In groups at discharge } \\
\text { Follow up }\end{array}$ & $X$ & & $\begin{array}{l}X \\
X\end{array}$ & & $\begin{array}{l}X \\
X\end{array}$ & & & & $\begin{array}{l}X \\
X\end{array}$ \\
\hline
\end{tabular}

characterised as multimodal rehabilitation, comprehensive cancer support and art therapy programmes. The programmes were run by patient associations, foundations or private enterprises and in a majority of programmes these organisations collaborated with funding sources and public healthcare. All programmes had a plan for evaluation and quality control, and reported a majority of satisfied clients.

The selection of programmes for participation was a challenge during the data collection because of ambiguous information from websites, foundations, and hospitals about current support- and rehabilitation programmes around the country. In total, eleven programmes fulfilled the inclusion criteria, meaning all cancer rehabilitation programmes in Sweden besides public healthcare clinics were covered at the point of the study, in the first half of 2011. All the programmes were secured to be anonymous. None of the programme representatives reported organisational discomfort due to participation or member defection as a result.

In a recently published study [22], it was reported that only two cancer clinics in Sweden focus on cancer rehabilitation. In addition, two smaller teams provide some rehabilitation of cancer patients. Sweden, with a population of 9.5 million, is geographically elongated and public healthcare cancer rehabilitation opportunities are not evenly spread throughout the country. Just one of nine centres included in this study is located in the north of Sweden. The need for cancer rehabilitation is not met by the public healthcare sector, so there is a demand for further resources.

Our results pointed out physical activities and therapies, for example, bath and physiotherapy. In international research interventions, exercise is described most frequently e.g. cycling, walking or strength training $[5,16,36]$. The combination of physical exercise and diet [15], as well as group-based 
psychosocial interventions such as health education, art therapy and relaxation $[1,20]$ are also described.

The results show that conventional medical consultation was provided in some of the programmes. Recent studies show that medical rehabilitation programmes have had an effect on cancer survivors' employment status. Six weeks after rehabilitation, $76 \%$ of the investigated persons had returned to work [37], and participation in support groups decreased anxiety over time [19]. As pointed out in the literature, improvement or deterioration in wellbeing as a result of interventions is multifaceted, and the specific result of the intervention is difficult to demonstrate due to progression of the disease and treatment-related outcomes [3]. For example, studies tend to highlight reductions in distress symptoms such as anxiety, fatigue and sleep disturbances, and increases in physical functioning, energy levels, body weight, mood, survival rate, and ability to return to work, health related quality of life and general quality of life and well-being [3-5, 16, 21, 22]. However, a recent Cochrane review [38] found that multidimensional rehabilitation programmes were more likely to support the physical needs of cancer patients than their emotional needs. Rehabilitation programmes are important not only for physical and psychosocial recovery, but also for the labour market reintegration of patients. Profound understanding of cancer and treatment-induced impairments and their impact on daily activities and work is an essential basis for the development of better educational, rehabilitative, and occupational interventions in cancer care [39].

Our results show that participants were not offered tailored interventions, and a critical but unanswered research question is how to screen patients in order to identify their need for psychological and social intervention [25]. The usual counselling was offered to groups, but also to individuals and couples. It is well known that family and friends frequently play a central role in providing support, along with health professionals. Such informal support may involve considerable physical, psychological and economic stresses [40]. Future research, which is suggested, could focus on patients' wellbeing and contentment with treatment addressing the requests of individual patients [41].

Our study is based on interview and documents but not on observations. In this study, the interview guide with open-ended questions was developed, discussed and modified by the research team and, according to [30] and [26] suggested three principle data sources for case studies: interview, observation and documentary data. In our study, the intention was to gain access to previous evaluations and patient-reported data. Additionally, the interviews were performed with representatives of the different providers and the documents studied were from websites. Both sources are eager to give a positive picture of the activities and outcomes of the organisation. Only two programmes consented to sharing evaluation reports and one programme consented to providing us with anonymous patient-reported data, which should be considered a major weakness, since no comparisons were then possible. In the literature, research into supportive and rehabilitation care is criticised for being methodologically incomplete and larger RCT studies are lacking [5, 21, 22, 25].

One of the underlying purposes of the study was to survey all the programmes in order to elucidate their different structures, content and activities and thus compare them with each other in an evaluation. The need for such an evaluation is obvious as there is an imminent need for more cancer rehabilitation programmes in Sweden as in the rest of Europe, and it is important to find out what is presently viable or not in order to plan ahead. When a follow-up of the cancer support and rehabilitation programmes was performed in 2013, about two years after data were collected in the present study, we discovered that some of the programmes had discontinued. These programmes could be seen as vulnerable, led by enthusiasts and person- linked. Quality improvement as well as representative, educated peer-support linked to patient associations and foundations may have contributed to the success and continuity of such programmes. Their discontinuation made it problematic to further compare and evaluate the cancer support and rehabilitation programmes found in this study. Regarding the focus of our study, when attention was given to a single behaviour outcome, for example, physical activities, programmes appeared to be more successful. Also the programmes that appeared to be more successful were brief programmes of less than six months in duration, comprising mixed groups of cancer patients encountering different type of health professionals. Future studies should therefore focus on patients' rehabilitation needs on multiple levels in combined therapies and seek to examine multimodal programmes, including various and multidimensional outcome indicators [22].

The questionnaires for evaluation identified HAD, SF-36, EORTC and FACT for outcome measurement are all described in the above-mentioned Cochrane review [38], but the present study also identified the questionnaire EQ-5D (Table 3). The selection of appropriate questionnaires to be utilised for the evaluation of cancer rehabilitation in the future is essential. Previously mentioned questionnaires measure quality of life in different aspects, but they do not measure patients' needs for rehabilitation efforts. Future research should focus on selection of appropriate questionnaires to be utilised for the evaluation of cancer rehabilitation in the future.

\section{CONCLUSION}

Swedish cancer support and rehabilitation programmes offer a variety of activities and therapies which are highly valuable and relevant for people with cancer. Based on the programmes' structures, processes and outcomes, three tentative types of programmes were identified: multimodal rehabilitation, comprehensive cancer support and art therapy programmes. Minor distinguishing characteristics between these three types were identified: multimodal rehabilitation programmes provided a broad range of combined therapies; comprehensive cancersupport programmes provided a combination of few therapies including single body-based therapies; and art therapy programmes offered support by means of one specific therapy. We nevertheless disclosed great similarities between multimodal rehabilitation and comprehensive cancer support programmes. With increasing number of cancer survivors in Europe, further empirical inquiry is needed, such as survey of cancer survivors' needs, to what extent they are met, and how to better respond to their needs (see also Baili et al.). In particular, the results raise questions for identification and selection of the most significant outcome measures in order to evaluate and further elucidate similarities and differences between types of cancer support programmes. In conclusion, it is clear that 
personal needs are unique, as is the individual's specific lifestyle, which gives reason to offer a range of support and rehabilitation programmes.

\section{CONFLICT OF INTEREST}

The authors confirm that this article content has no conflict of interest.

\section{ACKNOWLEDGEMENTS}

The study was financially supported by a grant from the Swedish Cancer \& Traffic Injury Society Fund.

\section{REFERENCES}

[1] Weis J. Support groups for cancer patients. Support Care Cancer. 2003;11(12): 763-8. [Epub 2003; Oct 15].

[2] Ernst E. Massage therapy for cancer palliation and supportive care: a systematic review of randomised clinical trials. Support Care Cancer 2009; 17: 333-7.

[3] Ben-Arye E, Steiner M, Karkabi K, et al. Barriers to Integration of Traditional and Complementary Medicine in Supportive Cancer Care of Arab Patients in Northern Israel. Evid Based Complement Alternat Med 2012; 2012: 1-9.

[4] Collinge W, Macdonald G, Walton T. Massage in supportive cancer care. Semin Oncol Nurs 2012; 28(1): 45-54.

[5] Mishra S, Scherer R, Snyder C, Geigle P, Berlanstein D, Topaloglu O. Exercise interventions on health-related quality of life for people with cancer during active treatment. Cochrane Database Syst Rev 2012; 15: CD008465(8).

[6] Mikkelsen T, Sondergaard J, Jensen A, Olesen F. Cancer rehabilitation: Psychosocial rehabilitation needs after discharge from hospital? Scand J Prim Health Care 2008; 26(4): 216-21.

[7] Cheville A, Kornblith A, Basford J. An examination of the causes for the underutilization of rehabilitation services among people with advanced cancer. Am J Phys Med Rehabil 2011; 90(27-37): S27-37.

[8] Watson P. Cancer rehabilitation. Cancer Nurs 1990; 13: 2-12.

[9] Stubblefield M. Cancer rehabilitation. Semin Oncol 2011; 38: 386-93.

[10] NCU. From needs to offers. Rehabilitation of cancer patients. Nordic Cancer Union 2004.

[11] Peteet J. A closer look at the concept of support: some application to the care of patients with cancer. Gen Hosp Psychiatry 1982; 4: 19-23.

[12] Berglund G, Bolund C, Gustavsson U, Sjödén P. Starting again-a comparison study of a group rehabilitation program for cancer patients. Acta Oncol 1993; 32: 15-21.

[13] Høybye M, Dalton S, Christensen J, et al. Research in Danish cancer rehabilitation: social characteristics and late effects of cancer among participants in the FOCARE research project. Acta Oncol 2008; 47(1): 47-55.

[14] van Weert E, Hoekstra-Weebers J, Grol B, et al. A multidimensional cancer rehabilitation program for cancer survivors: effectiveness on health-related quality of life. J Psychosom Res 2005; 58: 485-96.

[15] Davies N, Batehup L, Thomas R. The role of diet and physical activity in breast, colorectal, and prostate cancer survivorship: a review of the literature. Br J Cancer 2011; 8(105): 52-73.

[16] Groeneveld I, de Boer A, Frings-Dresen M. Physical exercise and return to work: cancer survivors' experiences. J Cancer Surviv 2013; 7(2): $237-46$

[17] Berglund G, Petersson L, Eriksson K, Häggman M. Between "men": patient perceptions and priorities in a rehabilitation program for men with prostate cancer. Patient Educ Couns 2003; 49: 285-92.
[18] Johnsson A, Tenenbaum A, Westerlund H. Improvements in physical and mental health following a rehabilitation programme for breast cancer patients. Eur J Oncol Nurs 2011; 15(1): 12-5.

[19] Granstam BH, Lindemalm C, Rosenblad A, et al. A randomised controlled trial of support group intervention after breast cancer treatment: results on anxiety and depression. Acta Oncol 2012; 51: 198207.

[20] Carlsson M, Strang P. Educational support programme for gynaecological cancer patients and their families. Acta Oncol 1998; 37: 269-75.

[21] Chan C, Wang C, Ho R, et al. A systematic review of the effectiveness of qigong exercise in supportive cancer care. Support Care Cancer 2012; 20(6): 1121-33.

[22] Hellbom M, Bergelt C, Bergenmar M, et al. Cancer rehabilitation: A Nordic and European perspective. Acta Oncol 2011; 50(2): 179-86.

[23] Verhoef M, Leis A. From studying patient treatment to studying patient care: arriving at methodologic crossroads. Hematol Oncol Clin North Am 2008; 22(4): 671-82.

[24] SOU. Rehabiliteringsrådets slutbetänkande Stockholm: Regeringskansliet 2011.

[25] Johansen C. Rehabilitation of cancer patients-research perspectives. Acta Oncol 2007; 46: 441-5.

[26] Payne S, Field D, Rolls L, Hawker C. Case study research methods in end-of-life care: reflections on three studies. J Adv Nurs 2007; 58: 23645.

[27] Stake R. Qualitative case studies. In: Denzin NK \& Lincoln YS, Eds. The sage handbook of qualitative research. $2^{\text {nd }}$ ed. Thousand Oaks: SAGE 2005

[28] Nausheen B, Gidron Y, Peveler R, Moss-Morris R. Social support and cancer progression: a systematic review. J Psychosom Res 2009; 67: 403-15.

[29] WHO. Knowledge into action cancer control WHO Guide for effective programme. http://www.who.int/cancer/modules/en/ 2005 [cited 2013 November 12].

[30] Donabedian A. The quality of care. How can it be assessed? JAMA 1988; 260: 1743-8.

[31] Schiff G, Rucker T. Beyond structure process-outcome: Donabedians seven pillars and eleven buttresses of quality. Jt Comm J Qual Improv 2001; 27: 169-74

[32] World Medical Association. Ethical Principles for Medical Research Involving Human Subjects website. http://www.wma.net/en/30publicati ons/10policies/b3/1964 [cited 201312 November].

[33] Zigmond A, Snaith R. The hospital anxiety and depression scale. Acta Psychiatr Scand 1983; 67: 367-70.

[34] Ware J, Snow K, Kosinski M, Gandek B. Health survey manual and interpretation guide. Boston: New England Medical Center 1993.

[35] EuroQol group. Euro Qol - A new facility for the measurement of health related quality of life. Health Policy 1990; 16: 199-208.

[36] Spence R, Heesch K, Brown W. Exercise and cancer rehabilitation: a systematic review. Cancer Treat Rev 2010; 36(2): 185-94.

[37] Mehnert A, Koch U. Predictors of employment among cancer survivors after medical rehabilitation - a prospective study. Scand J Work Environ Health 2013; 39(1): 76-87.

[38] Scott D, Mills M, Black A, et al. Multidimensional rehabilitation programmes for adult cancer survivors. Cochrane Database Syst Rev $2013 ; 28(3)$.

[39] Tamminga S, Verbeek J, Taskila T, Frings-Dresen M. Enhancing return-to-work in cancer patients, developement of an intervention and design of a randomised controlled trial. BMC Cancer 2010; 10: 345.

[40] Chambers S, Schover L, Halford K, et al. ProsCan for couples: feasibility study evaluating peer support within controlled research design. Phycooncology 2013; 22(2): 475-9.

[41] Ferrell B, Paice J, Koczywas M. New standards and implications for improving the quality of supportive oncology practice. J Clin Oncol $2008 ; 26(23): 3824-31$. 